\title{
COVID-19 Pandemic: Medical and Pharmacy Education in Nigeria
}

Yusuff Adebayo Adebisi, ${ }^{1}$ Progress Agboola, ${ }^{2}$ Melody Okereke. ${ }^{1}$

\begin{abstract}
The Experience
Coronavirus Disease 2019 (COVID-19) pandemic poses a major threat to education globally and medical and pharmacy education in Nigeria is not an exception. Although the focus has been to treat the infected persons and reduce the spread of the virus as much as possible, the emergence of COVID-19 has disrupted education and this requires prompt attention from stakeholders., ${ }^{1,2}$ The pandemic effect on healthcare students' education would be more pronounced because of its peculiarities as it involves clinical rotation exposure, laboratory experiences, internships, in-person didactic lectures and tutorials, presentations, clinical clerkship, observing and assisting relevant medical and surgical procedures.
\end{abstract}

A good number of healthcare students including medical and pharmacy students are in the process of preparing for or undertaking assessments that require clinical exposure. The effect of COVID-19 pandemic on healthcare students' education in Nigeria could therefore be considered significant, causing a disastrous effect to performance in examination post-pandemic and competency of these future healthcare professionals. As students, we cannot help but concern ourselves with how the COVID-19 pandemic will affect our career trajectories. The pandemic has equally reiterated the value of the skills and trainings that we gain in school. We are happy and proud to see healthcare students including medical and pharmacy students starting and organizing different programs aimed at improving public understanding and supporting responses to the COVID-19 outbreak.

Medical and pharmacy education were halted as a proactive measure to further curtail the spread of the virus. The National Universities Commission has ordered universities in Nigeria to close for a month beginning from 23 March 2020. ${ }^{3}$ As there is an upsurge in number of COVID-19 confirmed cases on a daily basis, schools across the country are likely to be closed indefinitely until there is a standard treatment option or vaccine for COVID-19. Consequently, medical training has been invariably affected, however, some private universities have explored the use of virtual platforms like Zoom, Telegram, WhatsApp, Coogle Classroom, and emails for academic activities. The effectiveness of these learning platforms in Nigeria has been questioned because of poor internet connectivity, relatively expensive out-of-pocket spending on internet data bundles and epileptic power supply.

Additionally, the COVID-19 pandemic has also affected proposed examinations in medical schools across the country. For instance, Progress Agboola's Bachelor of Medicine Part 2 assessment was postponed a few days to the exam due to the COVID-19 pandemic. It is without a doubt that this will have impact on students ranging from competency, mental health status to academic performance.

Crises like this provide opportunity for educators to leverage technology to sustain undergraduate and postgraduate medical education. ${ }^{4}$ To leverage on these opportunities, e-learning platforms can be utilized to deliver lectures remotely at one's convenience. Faculty, instructors and medical educators, residents, and students can then log in at scheduled time for discussions, which can be facilitated live using video and audio conferencing. In addition to lectures, video conferencing can also be leveraged to teach medical procedures and surgical techniques. ${ }^{5}$ However, required facilities to cope with these modern teaching approaches in Nigeria remain a major challenge.

Also, the COVID-19 pandemic has had its toll on pharmacy education globally and Nigeria is not left out. The pharmacy practice is continuously evolving worldwide and so is the need for a corresponding evolution of learning methods, ${ }^{6}$ which is especially crucial at this period of crises. The unprecedented nature of the pandemic has led to the unanticipated closure of all pharmacy schools in Nigeria thereby causing disruption and interruption of the pharmacy curriculum and examinations. For instance, Melody Okereke's exam was suspended indefinitely. This present situation has challenged the pharmacy education sector to also devise a coordinated response and deploy feasible interventions that will ensure uninterrupted learning and student assessment in case of any unforeseen crises.

The benchmark for pharmacy education in Nigeria encourages the use of lectures, tutorials, case studies, presentations, and practical sessions as methods of imparting knowledge to pharmacy students. 7 The most commonly used method is didactic method. While e-learning methods are employed in some pharmacy schools, ${ }^{8}$ the reality is that not all pharmacy schools are equipped with the necessary infrastructure and technological innovations to strive in the face of the pandemic. This, however, is due to the fact that infrastructure, access to teaching resources, development of academic staff, and quality research remain persistent challenges to the delivery of quality pharmacy education in Nigeria and other developing countries. ${ }^{9}$ While the e-learning approach seems to be plausible, some practical courses in both pharmacy and medical curriculum require a hands-on approach.

The lockdown policy and the need to practice physical distancing also have a significant effect on clinical rotations, internships and graduation of pharmacy and medical students as they are forced to

BPharm. Faculty of Pharmacy, University of Ibadan, Ibadan, Nigeria.

${ }_{2}$ MBBS. Department of Medicine \& Surgery, Faculty of Clinical Sciences, Ladoke Akintola University of Technology, Oyo State, Nigeria.

BPharm. Faculty of Pharmaceutical Sciences, University of Ilorin, Ilorin, Nigeria.

About the Author: Yusuff Adebayo Adebisi just finished his final exams at the Faculty of Pharmacy, University of Ibadan, Ibadan, Nigeria. Progress Agboola is a $4^{\text {th }}$ year medical student from the Faculty of Clinical Sciences, Ladoke Akintola University of Technology, Oyo State, Nigeria. Melody Okereke is a $2^{\text {nd }}$ year pharmacy student from the Faculty of Pharmaceutical Sciences, University of Ilorin, Ilorin, Nigeria.

Correspondence:

[Yusuff Adebayo Adebisi

Editor: Francisco Javier Bonilla-Escobar Student Editors: Nikoleta Tellios Submission: May 7, 2020

Address: Faculty of Pharmacy, University of Ibadan, Ibadan, Nigeria. Revisions required: May 13,2020 Email: adebisiyusuff23@yahoo.com 


\section{Experience}

remain at home until the pandemic is over. For instance, Yusuff Adebayo Adebisi completed his final examinations on 25 February 2020 but his induction into pharmacy profession was halted due to the COVID-19 pandemic. Him and his classmates are in state of dilemma whether they are still a student or graduate. This disruption has also cost some students opportunities to advance their career. Coing forward, this trend may also lead to a possible decline in the pharmacy workforce capacity, which has been documented in literature as one of the major challenges facing pharmacy practice in Nigeria. ${ }^{10}$
The COVID-19 pandemic creates a complex mixture of threats and opportunities for medical and pharmacy education in Nigeria and globally. The need to encourage e-learning in the modern world of education becomes clearly evident. ${ }^{11}$ In light of this, COVID-19 crisis makes it much-needed for the academic community, stakeholders and the Nigerian government to learn from this unprecedented pandemic to further review the future of medical and pharmacy education in Nigeria because there is no better time than now. 


\section{References}

1. Rose S. Medical Student Education in the Time of COVID-19. JAMA. 2020.

2. Bonilla-Escobar FJ. Leadership and Health: The Scientific Journal's Mission of Spreading Science in Times of Pandemic. Int J Med Students. 2020 Jan-Apr;8(1):9 10.

3. Azeezat. Adedigba. Coronavirus: NUC announces closure of Nigerian universities. Available from https://www.premiumtimesng.com/news/headlines/382880coronavirus-nuc-announces-closure-of-nigerian-universities.html; Cited 2020 May 2

4. Liang ZC, Ooi SBS, Wang W. Pandemics and Their Impact on Medical Training: Lessons From Singapore. Acad Med. 2020;10.1097/ACM.0000000000003441.

5. Lamba P. Teleconferencing in medical education: A useful tool. Australas Med J. 2011;4:442-447.

6. Lucero-Prisno III, DE, Adebisi YA, Micheal, Al, Ukor NA. Letter to the Editor: Pharmacy Education in Africa. Int J Health Life Sci. 2019;e89009
7. Pharmacists Council of Nigeria. Benchmark at Minimum Academic Standard. Available from http://www.pcn.gov.ng/files/BMS.pdf; Cited 2020 May 2

8. Ogaji, J, Ojabo CE. Pharmacy education in Nigeria: The journey so far. Archives of Pharmacy Practice. 2014;5(2).

9. Anderson C, Marriott IL, Carrasqueira J, Brock TP, Rennie T, Bruno AF, et al. Turning the world of pharmacy education into a global community through sharing. Am J Pharm Educ. 2014;78(7):130

10. Ekpenyong A, Udoh A, Kpokiri E, Bates I. An analysis of pharmacy workforce capacity in Nigeria. Journal of pharmaceutical policy and practice. 2018;11(1),20.

11. Federal Ministry of Education. A Coordinated Response to COVID-19. Available from http://education.gov.ng/education-a-coordinated-response-to-covid-19/; Cited 2020 May 2

\section{Acknowledgments}

None.

Conflict of Interest Statement a Funding

The Authors have no funding, financial relationships or conflicts of interest to disclose.

Author Contributions

Conceptualization: YAA, Writing - Original Draft Preparation \& Writing - Review ¿t Editing: PA, YAA, ¿ M0.

Cite as:

Adebisi YA, Agboola P, Okereke M. COVID-19 Pandemic: Medical and Pharmacy Education in Nigeria. Int J Med Students. 2020;8(2):162-4.

This work is licensed under a Creative Commons Attribution 4.0 International License 